Check for updates

Cite this: Chem. Commun., 2020, 56,6384

Received 10th March 2020

Accepted 29th April 2020

DOI: $10.1039 / \mathrm{d0cc01849j}$

rsc.li/chemcomm

\section{Unusually large fluorescence quantum yield for a near-infrared emitting DNA-stabilized silver nanocluster $\dagger$}

\author{
Vlad A. Neacşu, (D) $\ddagger^{\mathrm{a}}$ Cecilia Cerretani, $\ddagger^{\mathrm{a}}$ Mikkel B. Liisberg, (D) ${ }^{a}$ Steven M. Swasey, \\ Elisabeth G. Gwinn, ${ }^{c}$ Stacy M. Copp (D) de and Tom Vosch (D) *a
}

\begin{abstract}
A near-infrared emitting DNA-stabilized silver nanocluster (DNA-AgNC) with an unusually high fluorescence quantum yield is presented. The steady-state and time-resolved fluorescence properties of the DNA-AgNC were characterized, together with its ability to generate optically activated delayed fluorescence (OADF) and upconversion fluorescence (UCF).
\end{abstract}

DNA-AgNCs are a relatively new class of emitters, first introduced in 2004. ${ }^{1}$ DNA-AgNCs are composed of a limited number of silver atoms and cations (typically 2-30) wrapped in one or more DNA strands. ${ }^{2,3}$ The easiest way to tune the optical properties is by varying the DNA sequence, which has an effect on the type of silver cluster that can be stabilized. ${ }^{3-5}$ Not all DNA sequences yield DNA-AgNCs with useful properties, e.g. high brightness or photostability. In order to shed light on the relationship between DNA sequence and the optical properties of DNA-AgNCs, we have in recent years focused on studying the photophysical properties of HPLC-purified DNA-AgNCs; this step of purification ensures that a single type of emissive DNA-AgNC species is studied. ${ }^{6-9}$ Recently, crystal structure data of DNA-AgNCs has appeared in the literature, which will become a key part in understanding the relationship between DNA sequence and optical properties of the DNA-AgNCs. ${ }^{10,11}$

In this paper, we have studied the photophysical properties of a NIR-emitting DNA-AgNC, stabilized by the sequence

\footnotetext{
${ }^{a}$ Nanoscience Center and Department of Chemistry, University of Copenhagen, Universitetsparken 5, 2100 Copenhagen,Denmark.E-mail: tom@chem.ku.dk

${ }^{b}$ Department of Chemistry, University of California, Santa Barbara, California 93106, USA

${ }^{c}$ Department of Physics, University of California, Santa Barbara, California 93106, USA

${ }^{d}$ Department of Materials Science and Engineering, University of California, Irvine, California 92697-2585, USA

${ }^{e}$ Department of Physics and Astronomy, University of California, Irvine, California 92697-4575, USA

$\dagger$ Electronic supplementary information (ESI) available: Material and methods section, formation kinetics, HPLC data, additional steady state and time-resolved fluorescence data. See DOI: 10.1039/d0cc01849j

\# Both authors contributed equally.
}

$5^{\prime}$-CCCGGAGAAG-3'. This 10-base DNA oligomer was initially reported by Copp et al. in a study on the relationship between emission color and DNA sequence. ${ }^{4}$ The NIR part of the electromagnetic spectrum is of particular interest for imaging biological material due to regions of high transparency. ${ }^{12}$ However, a drawback of designing fluorophores in the NIR range is that, due to the small energy gap between excited state and ground state, non-radiative decay pathways tend to outcompete the radiative pathways, resulting in low fluorescence quantum yields. Thus, it is especially notable that the NIRemitting DNA-AgNC presented in this paper has an unusually high fluorescence quantum yield of $73 \%{ }^{13}$

The DNA-AgNCs were synthesized by mixing $5^{\prime}$-CCCGGAGAAG-3' with $\mathrm{AgNO}_{3}$ in a $10 \mathrm{mM}$ ammonium acetate $\left(\mathrm{NH}_{4} \mathrm{OAc}\right)$ solution. After 15 minutes, $\mathrm{NaBH}_{4}$ was added in order to reduce the silver cations. The ratio of the components in the final mixture was [DNA]: $\left[\mathrm{Ag}^{+}\right]:\left[\mathrm{BH}_{4}^{-}\right]=20 \mu \mathrm{M}: 100 \mu \mathrm{M}: 50 \mu \mathrm{M}$. A single fraction with a retention time around 12 minutes was collected by HPLC purification. Further information can be found in the (ESI $\dagger$ ). Fig. 1 shows the absorption and emission spectra of the HPLC-purified DNAAgNCs. The DNA-AgNC has an absorption maximum at $640 \mathrm{~nm}$ and an emission maximum centered at $721 \mathrm{~nm}$ at $25{ }^{\circ} \mathrm{C}$. Fig. 1B indicates a single type of emissive species, since no shift in the emission maximum versus excitation wavelength is found. ${ }^{14,15}$

Absorption and emission maxima recorded at different temperatures can be found in Table 1, which show no significant changes in the 5 to $30{ }^{\circ} \mathrm{C}$ range. Next, we determined the fluorescence quantum yield $(Q)$ at $25{ }^{\circ} \mathrm{C}$ which has a high value of $73 \%$. In order to test the temperature stability of the NIR-emitting DNA-AgNC, we applied several heating and cooling cycles to the DNA-AgNCs in a $10 \mathrm{mM} \mathrm{NH}_{4} \mathrm{OAc}$ solution. Fig. 2A shows 5 heating and cooling cycles from 10 to $40{ }^{\circ} \mathrm{C}$. From 5 to $30^{\circ} \mathrm{C}$ the fluorescence intensity changes linearly and reversibly with temperature. Above $30^{\circ} \mathrm{C}$ an irreversible loss in the overall fluorescence intensity is observed (see also Fig. S3, ESI $\dagger$ ). To confirm the reversibility in the $5-30{ }^{\circ} \mathrm{C}$ range, we repeated the experiment and the results can be seen in Fig. 2B. Fig. 2B demonstrates that the fluorescence intensity can be 

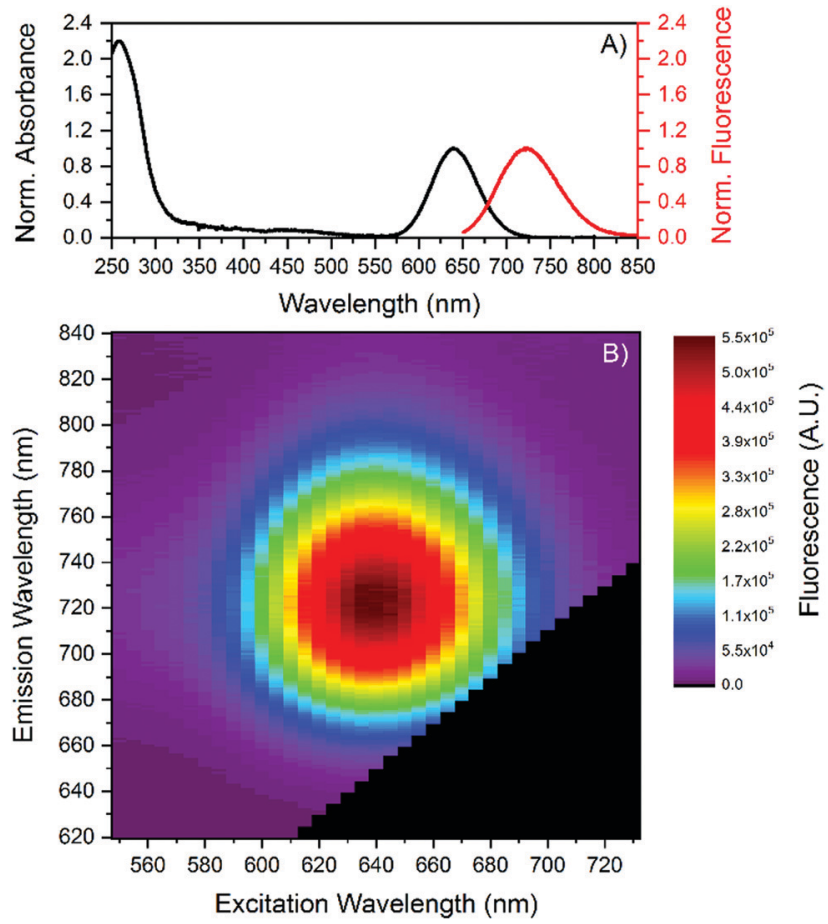

Fig. 1 (A) Absorption and emission (excited at $637.8 \mathrm{~nm}$ ) spectra of the purified DNA-AgNCs in $10 \mathrm{mM} \mathrm{NH}_{4} \mathrm{OAc}$ solution, recorded at $25^{\circ} \mathrm{C}$. Both spectra were normalized. (B) $2 \mathrm{D}$ emission vs. excitation plot of the purified DNA-AgNCs in $10 \mathrm{mM} \mathrm{NH}_{4} \mathrm{OAc}$ solution.

Table 1 Absorption and emission maxima, intensity-weighted average fluorescence decay time $\left\langle\tau_{w}\right\rangle$ and fluorescence quantum yield $(Q)$ at different temperatures. Emission data was recorded exciting at $637.8 \mathrm{~nm}$ for DNA-AgNCs in $10 \mathrm{mM} \mathrm{NH}_{4} \mathrm{OAc}$

$\begin{array}{lllllllll}\text { Temp. }\left[{ }^{\circ} \mathrm{C}\right] & -196^{c} & -78^{c} & 5 & 10 & 15 & 20 & 25 & 30 \\ \lambda_{\text {abs max }}[\mathrm{nm}] & & & 640 & 640 & 640 & 640 & 640 & 640 \\ \lambda_{\text {em max }}[\mathrm{nm}] & 706 & 710 & 721 & 721 & 721 & 721 & 721 & 721 \\ \left\langle\tau_{\mathrm{w}}\right\rangle^{a}[\mathrm{~ns}] & 3.63 & 3.74 & 3.75 & 3.74 & 3.74 & 3.73 & 3.72 & 3.72 \\ Q^{b} & & & & & & & 0.73 & \end{array}$

${ }^{a}$ Intensity-weighted average decay time, weighted by the intensity over the whole emission range. ${ }^{b}$ Terrylene diimide in toluene was used as a reference $(\mathrm{Q}=0.69) .{ }^{16}{ }^{c}$ Measurements performed in liquid nitrogen $\left(-196{ }^{\circ} \mathrm{C}\right)$ and a mixture of dry ice and acetone $\left(-78^{\circ} \mathrm{C}\right)$, respectively.

cycled quite reversibly in this temperature range. The change above $30{ }^{\circ} \mathrm{C}$ is due to an irreversible conversion to a different species with an absorption maximum in the $400-500 \mathrm{~nm}$ range (see Fig. S3, ESI $\dagger$ ). This new absorption feature could be due to silver nanoparticles formation, indicating a limited thermal stability of the DNA-AgNCs. The most intriguing observation however is the $Q$ value of $73 \%$ (see Fig. S5, ESI $\dagger$ ), which is very high for the NIR range. ${ }^{13}$ The lowering of fluorescence quantum yield for organic fluorophores with increasing wavelength can be rationalized by the smaller energy gap that starts to favor non-radiative decay over radiative decay. ${ }^{17}$ Conceptually, this can be explained by internal conversion from the excited state to an excited vibrational state in the ground state. As the energy gap between ground and excited state narrows, their respective vibrational energy levels (and overtones thereof) overlap more

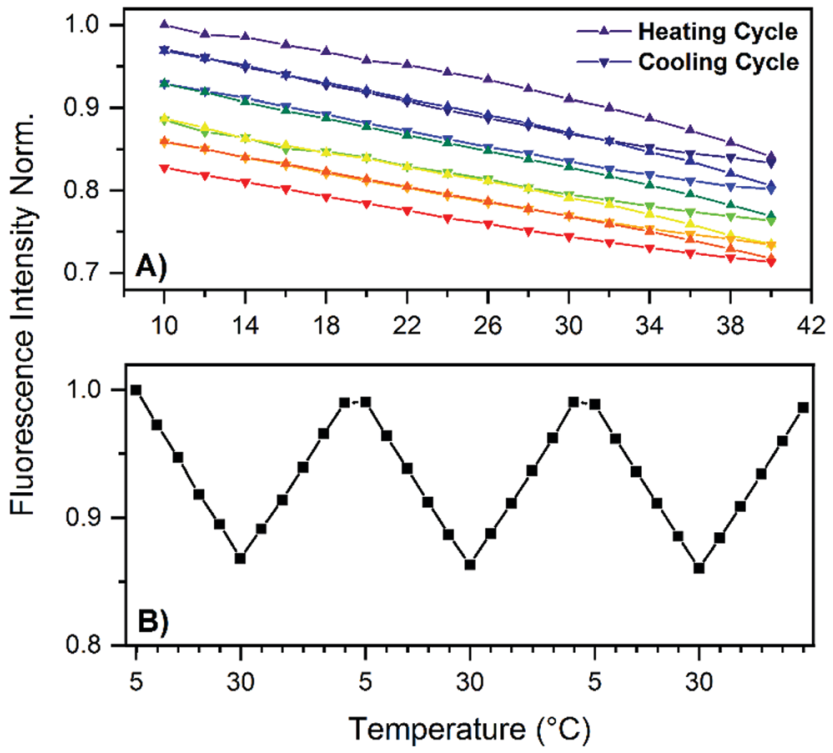

Fig. 2 (A) Fluorescence intensity of DNA-AgNCs as a function of temperature for five consecutive heating-cooling cycles: $10-40{ }^{\circ} \mathrm{C}$, in steps of $2{ }^{\circ} \mathrm{C}$. The fluorescence intensity is normalized to the initial fluorescence at $10{ }^{\circ} \mathrm{C}$. The cycles start with the purple color and end with the red color. (B) Emission intensity at $720 \mathrm{~nm}\left(\lambda_{\text {exc }}=637.8 \mathrm{~nm}\right)$ for three consecutive heating-cooling cycles, from $5-30{ }^{\circ} \mathrm{C}$, in steps of $5^{\circ} \mathrm{C}$. The fluorescence intensity is normalized to the starting fluorescence at $5{ }^{\circ} \mathrm{C}$.

and more. This is especially pronounced for organic dyes made from light elements that can form bonds with high vibrational frequencies, compared to heavier elements. ${ }^{18}$ A possible explanation for the high fluorescence quantum yield in our case is that the AgNC is weakly bound to the DNA scaffold (agreeing with the observed limited thermal stability), limiting solvent and/or DNA-mediated non-radiative decay. This could be a very important discovery, opening up the possibility to find other DNA-AgNCs that emit even further in the NIR, ${ }^{3}$ while retaining a high fluorescence quantum yield. Such fluorophores are currently missing and in high demand since they could find uses for in vivo tissue imaging. ${ }^{19}$ Time-resolved anisotropy measurements revealed that the NIR-emitting DNA-AgNC has a hydrodynamic volume of $19.6 \mathrm{~nm}^{3}$ (see Fig. S4, ESI $\dagger$ ), indicating that two, if not three, DNA strands stabilize this AgNC. The latter argument is based on comparing the hydrodynamic volume of another NIR-emitting DNA-AgNC composed of 16 silver atoms stabilized by two 10-base oligonucleotides ${ }^{8}$ which has a hydrodynamic volume of $10.5 \mathrm{~nm}^{3}$.

Coming back to the reversible fluorescence intensity change in the 5 to $30{ }^{\circ} \mathrm{C}$ range, the most obvious explanation for a temperature-dependent change in fluorescence intensity would be a change in $Q$ due to a temperature dependent non-radiative decay pathway. However, we just argued that this might not be the case here. One way to probe this is to measure the fluorescence decay at different temperatures, since the fluorescence decay time is the inverse of the sum of the radiative and non-radiative decay rates. Interestingly, unlike a previously studied red-emitting DNA-AgNC, ${ }^{7}$ whose $\left\langle\tau_{\mathrm{w}}\right\rangle$ changes with temperature, no significant difference $(\sim 1 \%)$ in the fluorescence 
decay time was observed for this NIR-emitting DNA-AgNCs in the $5-30{ }^{\circ} \mathrm{C}$ range (see Table 1 ). An intensity-weighted average fluorescence decay time of $3.72 \mathrm{~ns}$ was found at $25{ }^{\circ} \mathrm{C}$. It was shown before that longer DNA oligonucleotides (19-30 bases) generate DNA-AgNCs characterized by multi-exponential fluorescence decays due to slow spectral relaxation on the time scale of the fluorescence decay time. However, this NIR-emitting DNAAgNC, like another previously reported 10-base DNA-AgNC, ${ }^{8}$ seems to have an almost negligible amount of slow spectral relaxation, as can be seen in the time-resolved emission spectra (TRES) in Fig. S6 (ESI $\dagger$ ) and the reduced $\chi^{2}$ values for mono-exponential fits in Table S1 (ESI $\dagger$ ). Based on a phenomenological model of the electronic states presented by Cerretani et al. and Krause et al., ${ }^{7,20}$ this could mean that the temperature dependent change of fluorescence intensity is due to either a temperature-dependent quantum yield of the emissive state formation $\left(Q_{\mathrm{S} 1}\right)$ or due to a change in absorption with temperature and hence lowering the overall fluorescence, or a combination of both. Another scenario would be that the radiative and non-radiative rates change in opposite direction so that the sum is unaltered (this seems rather unlikely looking at the decay time measurements at $-78^{\circ}$ and $-196{ }^{\circ} \mathrm{C}$ discussed below and listed in Table 1).

Fig. S3 (ESI $\dagger$ ) shows a minor drop in the absorption from 10 to $25{ }^{\circ} \mathrm{C}$ of about $2.8 \%$. In this temperature range the fluorescence decreases about 7.9\%. This indicates that not all the loss of fluorescence can be attributed to a change in absorption, but there should also be an additional drop in $Q$. The change in absorption could be due to a temperaturedependent molar extinction coefficient or a reversible partial dissociation of the DNA-AgNCs. We did not determine $Q$ at different temperatures since the expected change is too small to be determined accurately. Instead, we decided to freeze the DNA-AgNCs to evaluate if very low temperatures affected the decay time in a way that could help interpret the photophysical properties. DNA-AgNCs in $10 \mathrm{mM} \mathrm{NH}_{4} \mathrm{OAc}$ were frozen in an NMR tube and the fluorescence decay times and emission spectra were recorded at $-78{ }^{\circ} \mathrm{C}$ (acetone/dry ice mixture) and $-196{ }^{\circ} \mathrm{C}$ (liquid nitrogen). The results of these experiments can be found in Fig. 3 and Table 1 . Surprisingly, the $\left\langle\tau_{\mathrm{w}}\right\rangle$ is nearly unchanged with a value of $3.74 \mathrm{~ns}$ at $-78{ }^{\circ} \mathrm{C}$. The emission spectrum narrows and blue shifts to a maximum centered at $710 \mathrm{~nm}$. Interestingly, the fluorescence decay time becomes multi-exponential, as can be seen by the rise in the average decay time as a function of emission wavelength in Fig. 3B and the TRES in Fig. S7 (ESI $\dagger$ ). The freezing restricts the conformational flexibility of the DNA-AgNC and the slow spectral relaxation on the timescale of the fluorescence decay time becomes visible again. This observation is in line with a previous report where changing the viscosity dramatically enhanced the slow spectral relaxation. ${ }^{8}$ However, it is still remarkable that even when the DNA-AgNC studied here is frozen solid, slow spectral relaxation occurs. The effect becomes even more pronounced at $-196{ }^{\circ} \mathrm{C}$ (see Fig. 3B). The emission spectrum narrows further and the maximum is now centered at $706 \mathrm{~nm}$. The $\left\langle\tau_{\mathrm{w}}\right\rangle$ at $-196{ }^{\circ} \mathrm{C}$ is $3.63 \mathrm{~ns}$, which is comparable to, but about $0.1 \mathrm{~ns}$ shorter than $\left\langle\tau_{\mathrm{w}}\right\rangle$ at room temperature. These observations lead
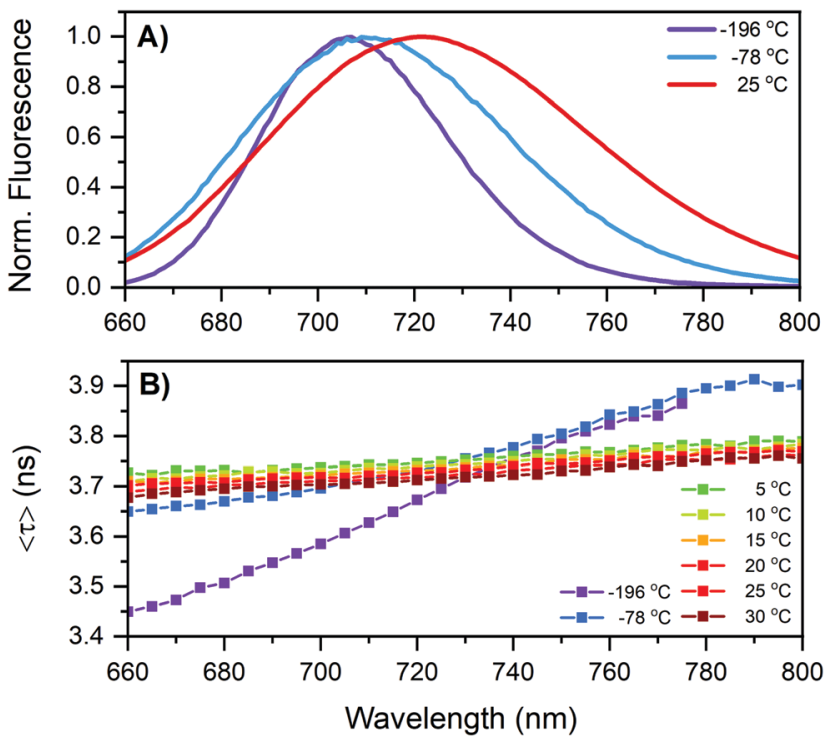

Fig. 3 (A) Normalized emission spectra of the DNA-AgNCs in $10 \mathrm{mM}$ $\mathrm{NH}_{4} \mathrm{OAc}$ at different temperatures ( $\lambda_{\text {exc }}=637.8 \mathrm{~nm}$ ). (B) Average decay time of DNA-AgNCs in the same solution as a function of emission wavelength at different temperatures.

us to conclude that non-radiative decay from the emissive state due to internal conversion must be negligible. Based on previous phenomenological photophysical models of DNA-AgNCs, we assume that $Q$ is the product of the quantum yield of emissive state formation $\left(Q_{\mathrm{S} 1}\right)$ from the Frank-Condon state and the fluorescence quantum yield from the emissive state $\left(Q_{\mathrm{fl}}\right){ }^{7}$

It has been previously demonstrated for a large number of DNA-AgNCs that dark state formation from the Frank-Condon state is a common process. ${ }^{20-27}$ This dark state can be optically excited by a secondary NIR laser that pumps the dark state to the emissive state in a process termed optically activated delayed fluorescence (OADF). ${ }^{20,23}$ We performed OADF measurements, since this allows to estimate the minimum value for the quantum yield of dark state formation $\left(Q_{\mathrm{D} 1}\right)$, as was previously demonstrated for a red-emitting DNAAgNC. ${ }^{20,28,29}$ After determining the OADF and upconversion fluorescence (UCF) contributions to the secondary fluorescence (SF, see ESI $\dagger$ for details) and normalizing it to the primary fluorescence (PF), a minimum $Q_{\mathrm{D} 1}$ value of $4.3 \%$ was found. ${ }^{20}$ This value is very similar to the minimum $Q_{\mathrm{D} 1}$ value of $3.9 \%$ previously found for a red-emitting DNA-AgNC. ${ }^{20}$ Interestingly, the contribution of UCF to the SF seems much higher here than for the red emissive DNA-AgNC. ${ }^{20}$ As demonstrated before ${ }^{20}$ the UCF signal is not due to a coherent two-photon absorption process, but a consecutive photon absorption process, since a rather linear relationship can be found for the UCF signal versus secondary excitation intensity (see Fig. 4A). ${ }^{28}$ The easily detectable OADF and UCF signals of this NIR-emitting DNA-AgNC make it an interesting candidate for anti-Stokes fluorescence imaging. ${ }^{20}$ Besides dark state formation, the Frank-Condon state could partially undergo ultrafast ground state recovery, as was demonstrated previously for red-emitting DNA-AgNCs. ${ }^{21}$ 

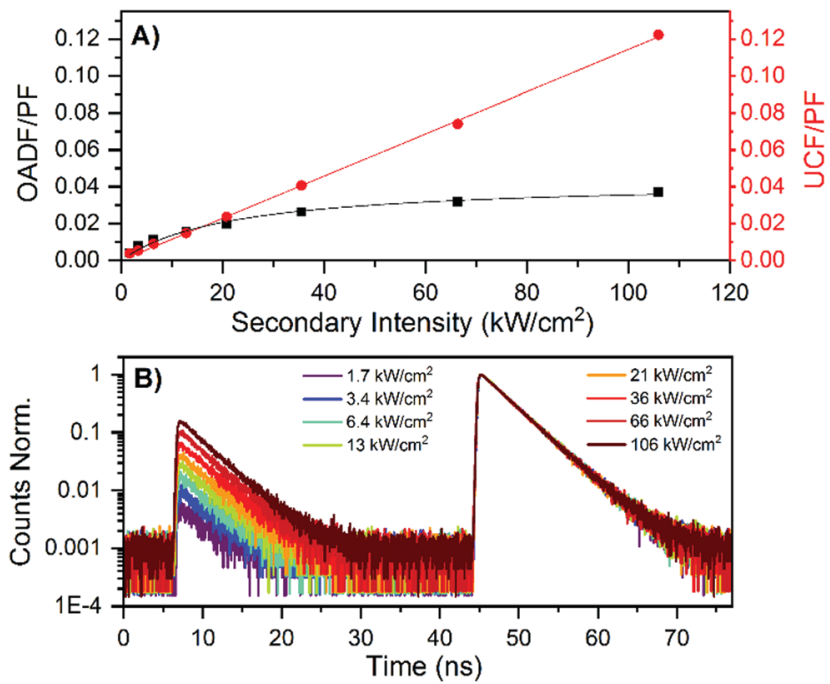

Fig. 4 (A) Contribution of OADF and UCF to the SF signal, relative to the PF signal. (B) Decay curves of the NIR-emitting DNA-AgNCs in $10 \mathrm{mM}$ $\mathrm{NH}_{4} \mathrm{OAc}$. The PF region (excitation with the $640 \mathrm{~nm}$ pulse, see Fig. S8A, $\mathrm{ESI} \dagger$ ) is from about 45 to $70 \mathrm{~ns}$, while the SF region (excitation with the $760-850 \mathrm{~nm}$ pulse, see Fig. S8A, ESI $\dagger$ ) is from 7 to $30 \mathrm{~ns}$. The primary excitation intensity was $127 \mathrm{~W} \mathrm{~cm}^{-2}$, whereas the secondary excitation intensity was varied from 1.7 to $106 \mathrm{~kW} \mathrm{~cm}{ }^{-2}$. Decay curves with only the secondary excitation to untangle the UCF from the OADF contribution can be found in Fig. S8B (ESI†).

In summary, we present a NIR-emitting DNA-AgNC with an unusually high fluorescence quantum yield of $73 \%$ at $25{ }^{\circ} \mathrm{C}$. This result suggests that there may exist more DNA-AgNCs further out in the NIR range that can maintain their high fluorescence quantum yield. These high fluorescence quantum yield NIR emitters are new and promising candidates for tissue imaging in the biological transparent NIR windows. We hypothesized that low coupling of the AgNC to the DNA bases could be the reason for both the high fluorescence quantum yield and the limited thermal stability. The NIR emitter converts irreversibly to a non-emissive compound upon prolonged heating above $30{ }^{\circ} \mathrm{C}$. Additionally, we demonstrated that this DNA-AgNC can produce easily detectable OADF and UCF signals that make it potentially suitable for anti-Stokes fluorescence imaging.

We acknowledge financial support from the Villum Foundation (Project number VKR023115), the Carlsberg Foundation (CF14-0388 and CF17-0470) and the Department of Chemistry, University of Copenhagen. The authors also thank Sruthi Gudibandi and Petko Bogdanov for their contributions to develop the DNA sequence reported here and Sidsel Bogh for performing initial exploratory measurements.

\section{Conflicts of interest}

There are no conflicts to declare.

\section{Notes and references}

1 J. T. Petty, J. Zheng, N. V. Hud and R. M. Dickson, J. Am. Chem. Soc., 2004, 126, 5207-5212.

2 D. Schultz and E. G. Gwinn, Chem. Commun., 2012, 48, 5748-5750.

3 S. M. Swasey, S. M. Copp, H. C. Nicholson, A. Gorovits, P. Bogdanov and E. G. Gwinn, Nanoscale, 2018, 10, 19701-19705.

4 S. M. Copp, A. Gorovits, S. M. Swasey, S. Gudibandi, P. Bogdanov and E. G. Gwinn, ACS Nano, 2018, 12, 8240-8247.

5 S. M. Copp, D. Schultz, S. Swasey, J. Pavlovich, M. Debord, A. Chiu, K. Olsson and E. Gwinn, J. Phys. Chem. Lett., 2014, 5, 959-963.

6 S. A. Bogh, C. Cerretani, L. Kacenauskaite, M. R. Carro-Temboury and T. Vosch, ACS Omega, 2017, 2, 4657-4664.

7 C. Cerretani, M. R. Carro-Temboury, S. Krause, S. A. Bogh and T. Vosch, Chem. Commun., 2017, 53, 12556-12559.

8 S. A. Bogh, M. R. Carro-Temboury, C. Cerretani, S. M. Swasey, S. M. Copp, E. G. Gwinn and T. Vosch, Methods Appl. Fluoresc., 2018, 6, 024004.

9 C. Cerretani and T. Vosch, ACS Omega, 2019, 4, 7895-7902.

10 D. J. E. Huard, A. Demissie, D. Kim, D. Lewis, R. M. Dickson, J. T. Petty and R. L. Lieberman, J. Am. Chem. Soc., 2019, 141, 11465-11470.

11 C. Cerretani, H. Kanazawa, T. Vosch and J. Kondo, Angew. Chem., Int. Ed., 2019, 58, 17153-17157.

12 R. Weissleder, Nat. Biotechnol., 2001, 19, 316-317.

13 K. Rurack and M. Spieles, Anal. Chem., 2011, 83, 1232-1242.

14 M. R. Carro Temboury, V. Paolucci, E. N. Hooley, L. Latterini and T. Vosch, Analyst, 2016, 141, 123-130.

15 C. M. Ritchie, K. R. Johnsen, J. R. Kiser, Y. Antoku, R. M. Dickson and J. T. Petty, J. Phys. Chem. C, 2007, 111, 175-181.

16 K. Kennes, Y. Baeten, T. Vosch, W. Sempels, S. Yordanov, S. Stappert, L. Chen, K. Müllen, J. Hofkens, M. Van der Auweraer and E. Fron, J. Phys. Chem. B, 2014, 118, 14662-14674.

17 J. R. Lakowicz, Principles of Fluorescence Spectroscopy, Springer, 3rd edn, 2006.

18 O. E. Semonin, J. C. Johnson, J. M. Luther, A. G. Midgett, A. J. Nozik and M. C. Beard, J. Phys. Chem. Lett., 2010, 1, 2445-2450.

19 R. Wang and F. Zhang, J. Mater. Chem. B, 2014, 2, 2422-2443.

20 S. Krause, M. R. Carro-Temboury, C. Cerretani and T. Vosch, Chem. Commun., 2018, 54, 4569-4572.

21 S. A. Patel, M. Cozzuol, J. M. Hales, C. I. Richards, M. Sartin, J. C. Hsiang, T. Vosch, J. W. Perry and R. M. Dickson, J. Phys. Chem. C, 2009, 113, 20264-20270.

22 I. L. Volkov, P. Y. Serdobintsev and A. I. Kononov, J. Phys. Chem. C, 2013, 117, 24079-24083.

23 B. C. Fleischer, J. T. Petty, J.-C. Hsiang and R. M. Dickson, J. Phys. Chem. Lett., 2017, 8, 3536-3543.

24 I. Volkov, T. Sych, P. Serdobintsev, Z. Reveguk and A. Kononov, J. Lumin., 2016, 172, 175-179.

25 J. T. Petty, C. Fan, S. P. Story, B. Sengupta, M. Sartin, J.-C. Hsiang, J. W. Perry and R. M. Dickson, J. Phys. Chem. B, 2011, 115, 7996-8003.

26 T. Vosch, Y. Antoku, J. C. Hsiang, C. I. Richards, J. I. Gonzalez and R. M. Dickson, Proc. Natl. Acad. Sci. U. S. A., 2007, 104, 12616-12621.

27 C. I. Richards, J. C. Hsiang, D. Senapati, S. Patel, J. Yu, T. Vosch and R. M. Dickson, J. Am. Chem. Soc., 2009, 131, 4619-4621.

28 S. Krause, C. Cerretani and T. Vosch, Chem. Sci., 2019, 10, 5326-5331.

29 S. Krause, M. R. Carro-Temboury, C. Cerretani and T. Vosch, Phys. Chem. Chem. Phys., 2018, 20, 16316-16319. 